\title{
Academic Research and Reform: A History of the Empirical Basis for NCAA Academic Policy
}

\author{
Todd A. Petr \\ NCAA \\ John J. McArdle \\ University of Southern California
}

\begin{abstract}
The purpose of this article is to provide an historical overview of the National Collegiate Athletic Association's (NCAA) academic reform, with a particular focus on the empirical basis for the decisions made. The authors outline four eras of academic reform, examine the types of information the NCAA has collected and used to make decisions about academic policy, and explore the limits of such academic data.
\end{abstract}

We have been conducting research on issues related to the academic success of student-athletes for the better part of two decades, and it is a pleasure for us to be able to share some of what we have learned here. We want to be clear that the data and findings that will be presented in this paper represent the hard work of lots of people other than just the authors, and we want to specifically acknowledge Ursula Walsh, Tom Paskus, Steve Boker, James Jackson, and the other members of the National Collegiate Athletic Association (NCAA) Data Analysis Research Network, and all our colleagues on the NCAA research staff for their significant contributions to this work.

We would also like to acknowledge all of the committed individuals who generously give their time and talent to sit on NCAA committees and wrestle with these difficult questions. Academic policy issues within the NCAA are complex and controversial. Everyone associated with intercollegiate athletics has an opinion on these issues, and the decisions made by these committees come under intense scrutiny. While none of us will agree with every decision that is made by these groups, the motives of the people who serve are beyond question. Committee members study reams of data and engage in sometimes-tortured discussions, but they work incredibly hard to get to the best possible solution for all Division I schools and students. It can be easy to second-guess their decisions from afar, but the people who sit in those rooms understand that the decisions they make affect real people in real

Petr is the NCAA Managing Director of Research, Indianapolis, IN. McArdle is with the Psychology Department, University of Southern California, Los Angeles, CA. 
ways. That can be a difficult burden, but we have been truly impressed by the way that NCAA committee members have responded to the challenge over the years.

In this paper, we provide a brief history of academic research at the NCAA and explain how data have been used to inform policy. We will look at the types of information the NCAA has collected and used to make decisions about academic policy, and we will look at the limits of such academic data. At the end of this paper, it is our hope that you have an appreciation for the complexity of the issues related to academic success of student-athletes and a better understanding of exactly how the NCAA has tried to use data to address those issues.

For purposes of this paper, we have divided the history of NCAA academic research into four "eras." We will certainly focus our attention on the last two eras-essentially the last 20 years. However, we want to provide a little bit of the history to shed some light on how we got to where we are today. The eras we have identified are not equal in scope of time, nor are they equal in the level of research activity, as you will see.

The genesis of NCAA academic research is, to a great extent, wrapped around the question of freshman (or initial) eligibility, as is the case with many elements of NCAA policy. Dr. Michael Oriard (2012) provides an excellent summary of the history of freshmen eligibility in his paper, so we will not rehash that here, but the freshman question certainly has driven much of our academic research, especially in the early years.

The first era of academic research that we have identified runs from the beginning of the NCAA in 1906 until about 1980. This might actually be best described as the prehistory of NCAA academic research. During that time, there was littleto-no research regarding student-athlete academic performance-at least from a national perspective. There was some research done surrounding the 1.6 minimum GPA (grade point average) rule in the 1960 s, but most of that work was at the institutional or conference level. It is fair to say that, to this point, the NCAA did not use research in a systematic way.

The second era in NCAA academic research comprises the 1980s. In that decade, there were significant changes in the eligibility rules made by the Association (e.g., Proposition 48), but, in the words of the NCAA's Director of Research at the time, Ursula Walsh, the policy was "remarkably free of empirical research." There were two primary catalyzing factors that led to the development and imposition of Proposition 48. The first was a series of high-profile academic scandals within intercollegiate athletics, including the identification of a few high-level student-athletes who had attended multiple years of college but were functionally illiterate. The second was a national movement to improve higher education as a whole that was exemplified by the influential governmental report titled "A Nation at Risk" (National Commission on Excellence in Education, 1983). That report was released the same year Proposition 48 was passed, and that is probably not coincidental. Proposition 48 was sponsored as NCAA legislation by the American Council on Education - a group that was intimately involved with the larger reform efforts occurring within the higher education community.

Thus, Proposition 48 was adopted within a climate of national educational reform and with substantial support from the membership, but there was not any specific research undergirding the legislation. Significant questions arose on the floor of the 1983 NCAA Convention, at which Proposition 48 was adopted, about how 
the legislation would impact low-income and minority students. These questions persisted even after the adoption of the legislation, and at that time there were no data available to provide empirical answers. In response, the NCAA membership created a special committee to study the issues, and that committee recommended that the NCAA undertake a longitudinal study to better understand the impacts of the new academic regulations. That became the NCAA Academic Performance Study (APS) and was the NCAA's first real effort to collect data from its member schools on these issues. Data from that study served as the backbone for the inquiries that were undertaken in the third era of NCAA academic research.

In the 1980s, in the midst of the discussions related to Proposition 48, Ron Smith and Jay Helman (1987) wrote an excellent paper on the history of the freshman-eligibility question. In that paper, they identified three sources of tension that drove historical policy decisions related to the issue: academic integrity, competitive equity, and financial considerations. In simple terms, the argument was that at times and in places where academic integrity was the primary consideration, freshmen would be ineligible for athletics competition. Conversely, when financial issues were driving policy decisions, freshmen would be eligible to compete because schools would be able to field competitive teams less expensively by being able to include freshmen on their rosters. Competitive-equity concerns have been used to argue this issue from both sides, generally depending on the size of the school making the argument.

These considerations continue to be germane to any discussion of NCAA academic policy; however, a fourth very important consideration has been added to the mix in current discussions of these issues: educational access for low-income and minority populations. Because of large differences in secondary education in this country, these rules do not affect all populations of prospective student-athletes in the same way. One can argue athletics is the route to a college education for many students from disadvantaged backgrounds and that restricting those students' access to an athletics scholarship essentially closes the door to a college education for them. Since the late 1980s, the issue of access has been at the forefront of any discussion of NCAA initial eligibility regulations.

It was about 1990 when the NCAA had collected sufficient academic data to begin to conduct its own analyses of impacts of academic policies on studentathletes. This ushered in what we have identified as the third era of academic research, and we will concentrate the rest of this paper on our work in this era. Issues studied during this time included high school academic performance and initial eligibility, college academic performance and continuing eligibility, and the best ways to measure team-level academic success. During this era, we also came to understand certain limits of how data can inform and shape policy. For instance, we made the important separation between objective indices and subjective decisions. Specifically, we found that there was much data that could be informative on specific issues (e.g., that high school grades and test scores were useful predictors of college success), but there were limits to the data and points where decisions would have to be made by group consensus (e.g., exactly where to set cut-scores on eligibility rules).

Before discussing specifics about findings from our research over the past two decades, it is important to provide some general background about the data on which many of these findings are based. The majority of results from the third 
era of academic research come from data collected in the APS. In that study, the NCAA collected both high school and college academic data in a longitudinal manner from over 10,000 Division I student-athletes across five cohorts (from 1984 to 1988). Thus, data were collected from two cohorts of student-athletes who entered college before Proposition 48 was implemented and from three cohorts postimplementation. In 1994, the NCAA began certifying the eligibility of all incoming-freshmen student-athletes. And while the driving force behind this effort was related to compliance and equity concerns, this was a huge boon for our academic research. The Initial Eligibility Clearinghouse (IEC), as it came to be known, collected complete high school academic records from over 100,000 prospective student-athletes each year. (The IEC has since been transformed into the NCAA Eligibility Center, or NEC, but the data collection remains a very important part of our research efforts.) Between 1994 and 2002, the NCAA collected college-level data on Division I student-athletes on a voluntary basis through the Academic Performance Census (APC). In that collection, data were gathered on between 10,000 and 20,000 student-athletes per year. With the implementation of the Academic Performance Program (APP) in 2003, Division I institutions were required to submit academic data on all of their scholarship student-athletes. The Association now receives college-level academic data from over 100,000 student-athletes per year, and by matching data from the NEC to the APP, the NCAA is able to create complete longitudinal academic records on Division I student-athletes from the time they are in high school until they exit the Division I institutions. These data are the best we are aware of in higher education regarding the complete academic trajectories of a national sample of high school and college students (for more information on NCAA data, see Petr \& Paskus, 2009).

We will now describe a few specific results from the third era of academic research at the NCAA. A first set of findings has to do with our ability to predict college success. Over the course of the past two decades, we have run many models attempting to predict college academic success from precollege variables. Through most, if not all, of these models, a few findings stand out:

- High school grades are better predictors of success than standardized test scores. In most of our models, grades are 2-3 times more predictive than test scores.

- A combination of grades and tests is a better predictor than either of the two variables used in isolation. The incremental benefit of including test scores in a prediction model is generally small, but meaningful.

- Using a core-curriculum grade point average (GPA) provides better prediction than using the overall high school GPA. We have noted that our prediction accuracy has improved as we have increased the number of courses included in the core-curriculum requirement.

- Demographic variables, such as income and race/ethnicity, are important attributes to consider in the models but are generally accounted for once tests and grades are included in the model.

- Different demographic groups have different distributions of scores within the variables of use (e.g., test scores and grades), so the imposition of almost any rule will lead to differential impacts on various subgroups. Generally speaking, African American and low-income students are more likely to be impacted 
by any rules that use grades and/or tests as criteria. However, this is due to distributional differences in those variables as opposed to differences in the actual predictive validity of the measurements.

These results have led NCAA committees to attempt to craft rules that use tests and grades in conjunction with each other and to weight grades equally or slightly higher than test scores. In addition, the impacts on different subgroups are always studied and efforts are made to minimize adverse impacts without harming the integrity of academic policy.

A second result that has been consistent over time is that use of a single cutscore on standardized tests is not advisable. While this continues to be a very controversial topic and passionate arguments continue to be made for the reimposition of a standardized test cut-score in NCAA initial eligibility legislation, we would argue that this is one issue on which the national data are quite clear. There is a consistent set of factors that have led NCAA policy makers to avoid the use of such a cut-score in NCAA academic regulations over the last decade. These include:

- Psychometric experts at the testing companies are in agreement that using test scores as a single factor in high-stakes decisions is an inappropriate use of standardized tests. The testing agencies have been on public record against using a single cut-score on the tests since Proposition 48 was adopted in 1983.

- As used in Proposition 48 and Proposition 16, the test cut-score led to tests being overweighted by a 2-to-1 margin as compared with high school GPA. As stated above, this weighting runs counter to our prediction models, which indicate grades should be weighted equal to or higher than tests.

- Regulations that overweight the test score tend to decrease overall accuracy of our predictions and lead to increases in adverse impact within certain demographic subgroups.

- Use of a single cut-score can lead to differential initial eligibility decisions for student-athletes with the same predicted chance of success.

- There is evidence that use of a cut-score simply changes student testing behavior, but does not necessarily make for better-prepared student-athletes.

We would like to turn now to a bit of the evidentiary data that underlie some of the conclusions mentioned above. To begin with, we provide some information on the actual academic outcomes of student-athletes with various incoming academic profiles.

In Figure 1, we have presented data on freshman-year academic outcomes of various groups of student-athletes based on incoming high school grades and test scores. The $y$ axis represents core-curriculum grades in high school, and the $x$ axis represents standardized test scores (in SAT units). The diagonal line that runs through this chart indicates the sliding scale that is currently in use as the minimum for initial eligibility for Division I student-athletes in conjunction with a 2.0 high-school-core GPA (HSCGPA) minimum. Those student-athletes represented by the Low-Test highlighted area in the upper left of this figure are student-athletes who have fairly high GPAs, but relatively low test scores. The student-athletes in this group were declared ineligible under both Propositions 48 and 16 because of the 820 test score-cut, but have become eligible under the sliding scale that was implemented in 2003. We compare those in this group to those in the Low-HSCGPA 


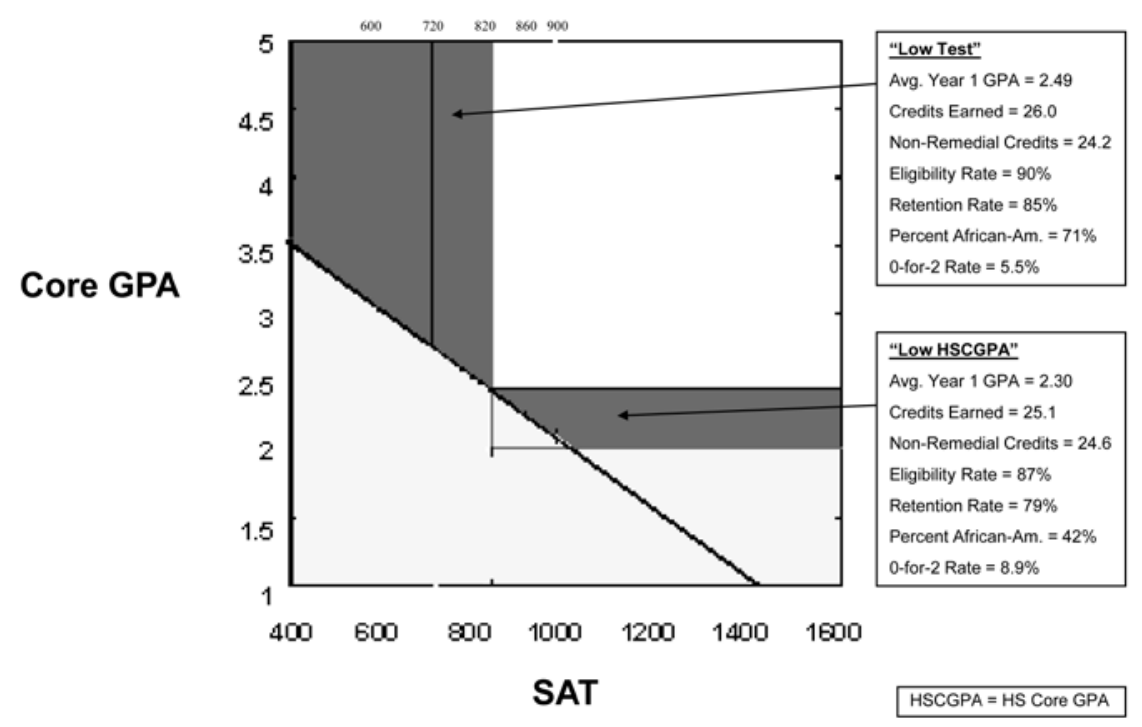

Figure 1 - First-Year Academic Performance of Low-Test vs. Low-GPA Qualifiers in Division I (2009-10 Division I Freshmen)

group represented in the lower right area of this chart, who have relatively high test scores, but lower GPAs than most other student-athletes. This group has been fully eligible under all recent NCAA initial eligibility regulations. Illustrated in the figure, members of the newly eligible group represented in the upper left of the figure are out performing those in the Low-HSCGPA group in most measured areas of freshman academic performance, including freshman GPA, eligibility rate, retention rate, and number of academic failures (labeled here as " 0 -for-2" student-athletes). It is also important to note that student-athletes represented in the Low-Test area are much more likely to be minority student-athletes than those who have always been eligible in the Low-HSCGPA area. We have been conducting similar analyses for over a decade, and the findings shown here from the 2009-2010 freshmen have been consistent from before the 2003 changes in the initial eligibility rules, on through the most recent data available.

It is, of course, possible that the freshman-year academic differences observed in the previous figure would not maintain through a college career. Thus, we can also look at longer term academic outcomes for these groups of student-athletes.

In Figure 2, data for the 2003-2004 entering freshmen class related to 5-year academic outcomes are presented. When comparing the newly eligible Low-Test group (see Figure 2, upper left) to the Low-HSCGPA group (lower right), we see similar results to those observed in the freshman-year outcomes. Specifically, the newly eligible student-athletes show a higher proportion of graduates (by between 8 and 9\%), and a lower proportion of academic failures (by between 7 and $8 \%$ ). These data make it clear that any rule that excludes the group represented in the Low-Test area but includes those represented in the Low-HSCGPA area is very difficult to defend. This consistent finding over time has played a very strong 


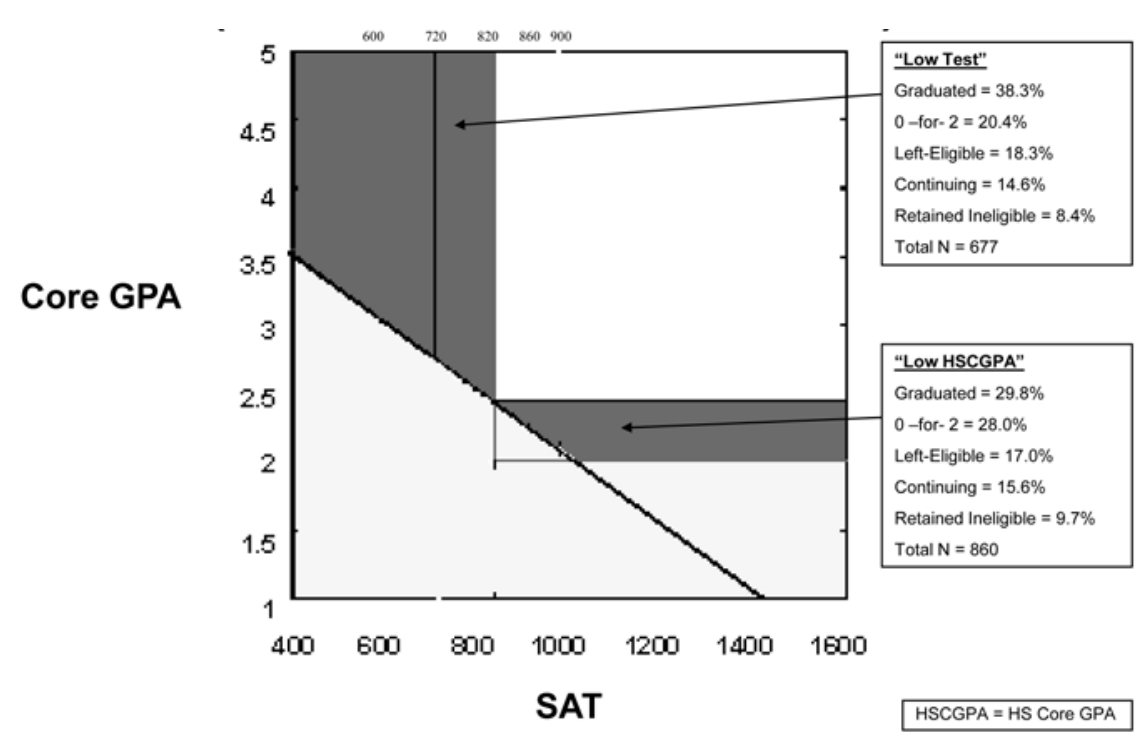

Figure 2 - Five-Year Academic Performance of Low-Test vs. Low-GPA Qualifiers in Division I (2003-04 Division I Freshmen)

role in committee decisions to remove the cut-score on the standardized tests and move to a full sliding-scale approach that combines test scores and grades in initial eligibility regulations.

Figure 3 provides interesting information on the observed impacts on testtaking behavior of student-athletes when faced with a cut-score on a standardized test and the ability to take the test as many times as necessary to achieve a qualifying score - as was the case in both Proposition 48 and Proposition 16. The top graph in Figure 3 shows the distribution of test scores among prospective studentathletes in 2002, the final year of the use of an absolute cut-score in NCAA initial eligibility legislation. Instead of a smooth curve that is normally distributed, we see a "cliff" in the distribution that appears just above the cut-score minimum of 820 on the SAT. The next three graphs in the figure show the 3 subsequent years (after the cut-score was removed), and we observe a significant smoothing of the distribution and the cliff that had been evident in the top graph essentially disappears. This provides evidence that student-athletes under a rule, which included a cut on the test score, simply took the test enough times to artificially raise their scores to a point that was above the minimum score. When considering the majority of student-athletes who were below the cut on their initial attempt were within 50 points of the minimum score, such leveraging of subsequent test-taking opportunities seems very possible. There is no evidence, however, that achieving a minimum standard through repeated testing led to student-athletes who were better prepared for college academic coursework.

Before we leave this important topic, we want to highlight one finding from our most recent graduation success rate (GSR) data that is related to these issues. The changes in initial eligibility standards that were implemented in 2003 had 

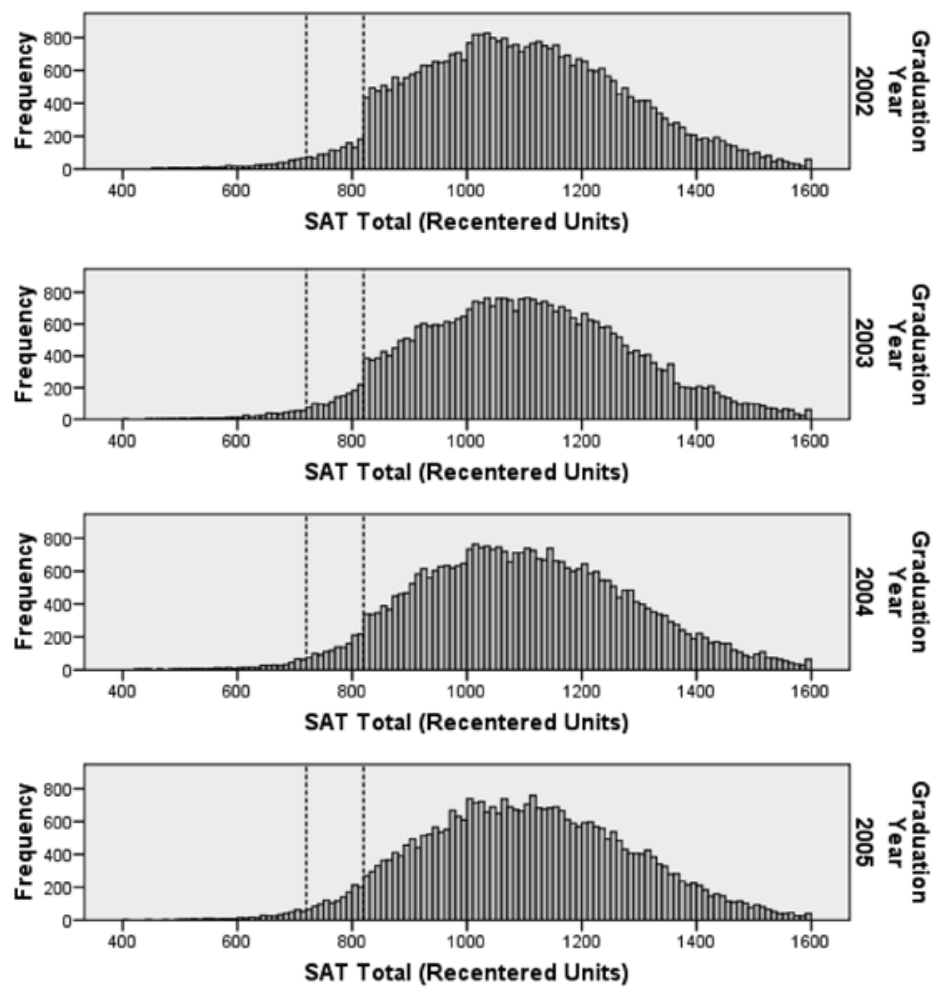

Figure 3 - Best SAT score among PSAs on a Division I IRL in 2002 (Prop 16) vs. 20032005 (Sliding Scale)

two goals: to maximize academic success and to minimize adverse impact on low-income and minority student-athletes. Data from the recent GSR indicate that these goals are being met.

Specifically, as Figure 4 shows, the proportion of minority student-athletes in the GSR cohort (represented by the upper line in the chart) and the proportion of minority graduates (represented by the lower line) dropped after the imposition of Proposition 16 in 1995. Those numbers stayed at post-Proposition 16 levels until the new eligibility rules went into effect in 2003, removing the cut-score on the test. In that 2003 cohort, we saw large increases in both the proportion of African Americans in the overall GSR cohort and among graduates. These trends continued with the 2004 cohort. These increases in minority representation come at the same time we have seen strong positive change in GSRs within all sport groups, indicating that overall academic performance is up, as well as the representation and academic success of minority student-athletes.

In a third overall finding from era three, we noted that the high school and college the student-athletes attend matter because these institutions are not all the same. This may seem fairly obvious, but it is an important and nontrivial consideration. In 


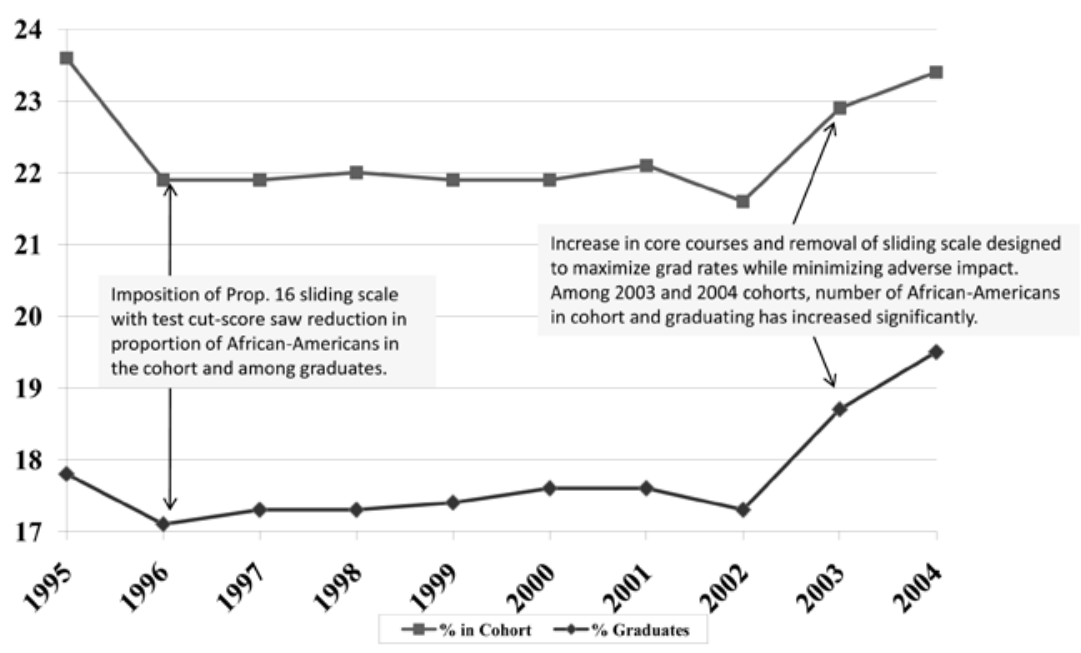

Figure 4 - Proportion of African-American Student-Athletes Among GSR Cohort and GSR Graduates 1995-2003

evaluating our statistical models, it was clear taking into account characteristics of the colleges student-athletes would attend could enhance our predictions of success. However, any potential rule providing differential access to the pool of recruits for different colleges was deemed unacceptable due to competitive equity concerns. Because of that practical reality, it is important to remember NCAA standards are national minimums that must account for student profiles and institutional missions at over 300 very diverse institutions. Because of this wide disparity in institutional missions and philosophies within Division I, these rules are in no way meant to substitute for institutional admissions policies or for thoughtful review of studentathlete admissions on each and every member campus.

A fourth important result from this era of academic research is that our predictions of academic success are better if the measurements of the predictor variables are closer in time to the academic outcome of interest. When we first began modeling predictions of academic success, we put a lot of emphasis on the prediction of college graduation from high school academic variables. However, models predicting graduation were much less accurate than those that predicted freshman academic success using high school variables. As we looked further into these models, it became clear that, while high school grades and test scores were the best predictors of freshman academic outcomes, first-year college outcomes are much better predictors of eventual graduation. These findings led to what became known as the "seamless" model of eligibility regulations, where freshman-eligibility rules are based on high school academic variables, but the progress-toward-degree (PTD) standards are based on in-college academic profiles of eventual graduates.

We want to say a bit more about the development of the current PTD standards. While there had been continuing eligibility standards in place through the 1980s 
and 1990s, those standards were set at levels that seemed to have minimal impact on student-athlete academic performance. These regulations were modified in 2003 and include minimum percent-of-degree regulations (e.g., the 40-60-80 advancement standards) and minimum continuing GPA standards for student-athletes as they progress through their collegiate academic careers. In developing these standards, our research in this area focused on the in-college academic trajectories of successful student-athletes. Specifically, rules for both percentage of degree earned and year-by-year GPA minimums were based on the observed distributions of all student-athlete graduates and were set at the fifth to 10th percentile of those distributions. Thus, the rules were set at levels that approximately $95 \%$ of actual graduates were attaining on a year-by-year basis. However, far fewer nongraduates were performing at these levels under the old rules. The goal here was to create policy that would require all student-athletes to be put on an academic trajectory that would be more likely to lead to graduation.

It is interesting to note that differential behaviors between graduates and nongraduates are evident very early in college and continue throughout enrollment. Figure 5 shows average credits earned for the nongraduates (as shown in group on left) versus the graduates (on the right) on a year-by-year basis. As you can see, the nongraduates earn significantly fewer credits beginning in the freshman year and moving through every year thereafter in their college careers. The goal of the new PTD legislation is to move student-athletes who would have been in the group represented on the left in the figure into an academic profile that puts them in the distribution of scores seen in the group on the right.

As another example of the thinking behind the setting of specific PTD standards, Figure 6 shows estimated impacts of various second-year GPA regulations. As with the initial eligibility standards, the goal with the PTD regulations is to

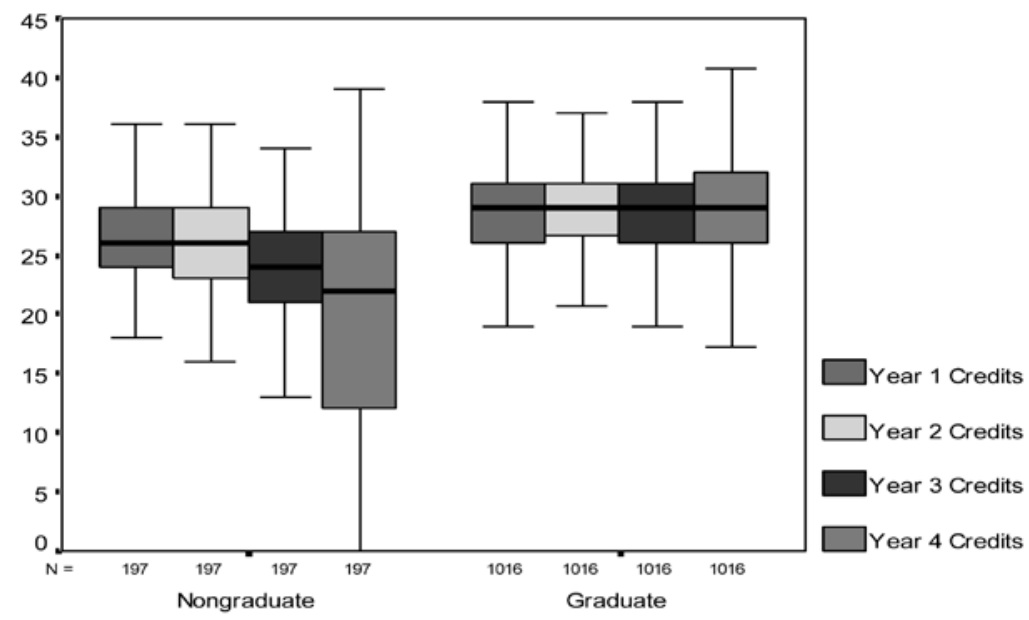

Graduation Status

Figure 5 - Academic Year Credit Hours for Graduates vs. Non-Graduates Persisting Four or More Years 
maximize academic success, while minimizing inaccuracies and, especially, adverse impacts. The chart on the left of Figure 6 illustrates the level of accuracy we have with various selections in terms of predicting eventual academic success by using cumulative GPA at the end of the second year as a selection mechanism. As you can see, moving from no rule to a minimum 1.9 GPA increases the accuracy of our selections. However, in the groups studied here, there is no noticeable increase in accuracy beyond the 1.9-GPA level. Conversely, the chart on the right shows the false negative rates for various levels of GPA. Obviously, the goal of any rule should be to minimize the rate of false negatives. In this chart, we see that the rate of false negatives for all subgroups is very similar through the 1.9-GPA level. However, we begin to see significant separation of those rates among minority student-athletes as we move to the 2.0 level. It was the combination of no measurable increases in accuracy with this noticeable shift in false negatives among minority student-athletes that caused the NCAA membership to set the second-year GPA rule at a minimum of 1.9. Similar analyses were used to assess all potential GPA and percent-of-degree eligibility rules for all 4 (or 5) years of collegiate enrollment.

The final set of findings we will highlight from this era of academic research has to do with the overall academic performance of student-athletes and observed impacts of NCAA academic legislation. Specifically, what we observed throughout our data analyses in the 1990s was that student-athletes, on average, tended to behave academically in a fashion that was very similar to the overall student body and that changes in NCAA academic rules corresponded with positive changes in student-athlete academic success. In another finding, the graduation rates of Division I student-athletes have been slightly higher than those of their nonathlete peers. This finding is more noticeable when we compare student-athletes to similar demographic subgroups within the overall student population.

(a) Classification Accuracy

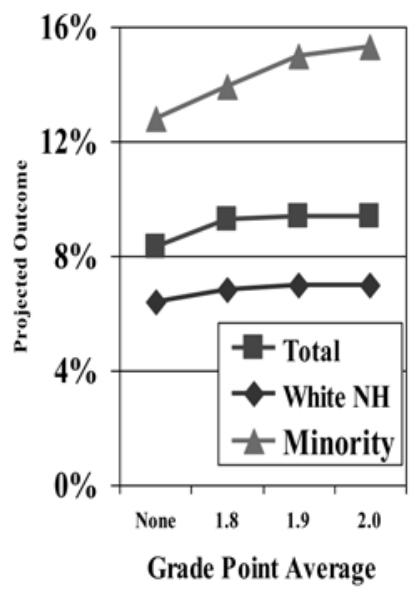

\section{(c) False Negatives}

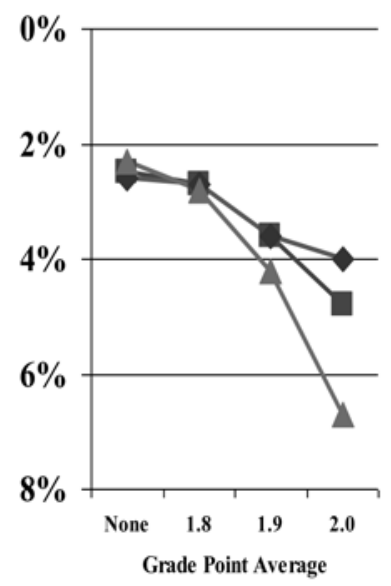

Figure 6 - Projected Impacts for Varying GPA (0 to 2.0) and 48 Credit-Hour Requirements in Second Year(Based on Data from 2000 NCAA Graduation Cohort) 
Figure 7 illustrates the trajectory of student-athlete and student body federal graduation rates (FGR) over the 21-year period for which we have been collecting these rates. As is seen in the graph, since the implementation of Proposition 48, student-athlete graduation rates have tended to be 1-3 percentage points above those for the general student body in Division I across this entire period of time. It is also evident that the largest single-year increases for student-athletes correspond with changes in NCAA eligibility standards that occurred in 1986 (imposition of Proposition 48), 1995 (increase in number of core courses), and 1996 (use of sliding scale as imposed by Proposition 16). There is evidence in both GSR and FGR data that recent academic changes will also lead to improved academic performance among student-athletes.

Table 1 illustrates differences between student-athletes and the general student body within various demographic subgroups on the FGR. There are two points to highlight in this table. First, while the overall student-athlete rate is two percentage points higher than the student-body rate, some of the demographic subgroups show significantly greater differences. For instance, White female student-athletes are 6 percentage points higher than White females in the general student body. Among African-American student-athletes, males are 12 percentage points higher than their student-body counterparts, and females are a full 20 percentage points higher as a group than African-American females in the student body. Only White male student-athletes trail their student body demographic counterparts. Second, though, are the clear differences in gender and ethnic subgroups within the student-athlete population. We continue to be concerned with graduation rates of some of these groups-particularly African-American males. There is good news in that the rate for that group of student-athletes is higher than it has ever been-and is up 17 percentage points from when the graduation rates data were first collected. However, the disparity between that group and other student-athletes is still of concern. As a
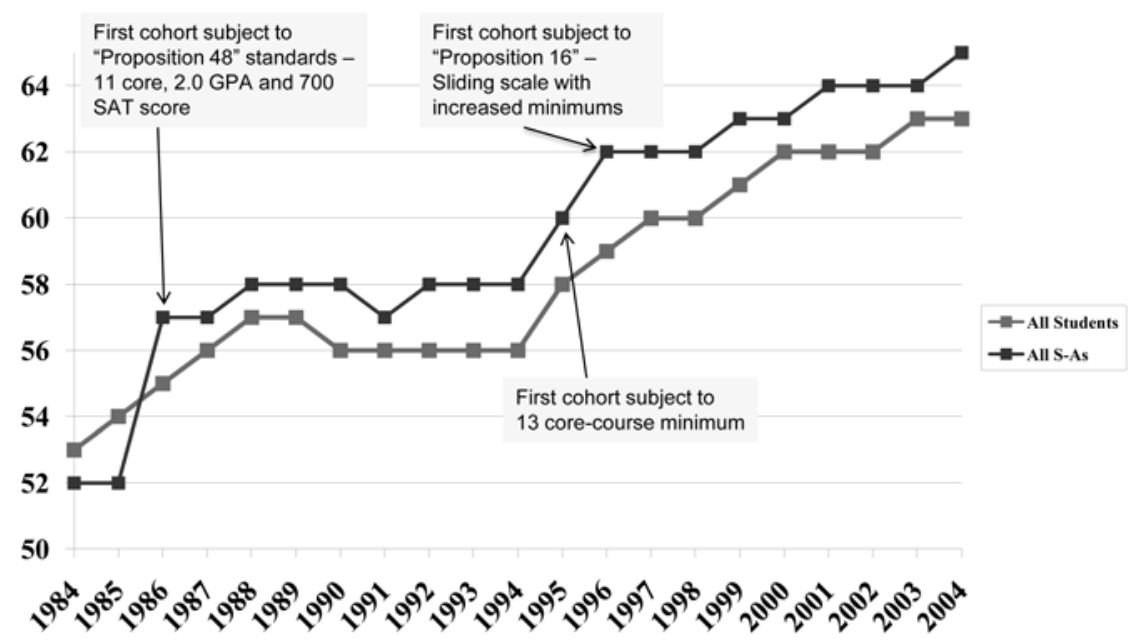

Figure 7 - Federal Graduation Rates of All Student-Athletes versus All Students at Division I Institutions 


\section{Table 1 Comparison of Federal Graduation Rates Between Student-Athletes and Student Body For Select Groups in 2004 Entering Class}

\begin{tabular}{lcc}
\hline $\begin{array}{l}\text { Student-Athlete } \\
\text { Group }\end{array}$ & $\begin{array}{c}\text { Student-Athlete } \\
\text { Graduation Rate }\end{array}$ & $\begin{array}{c}\text { Student Body } \\
\text { Graduation Rate }\end{array}$ \\
\hline Overall & $65 \%$ & $63 \%$ \\
White & $68 \%$ & $66 \%$ \\
African-American & $55 \%$ & $44 \%$ \\
White Males & $62 \%$ & $63 \%$ \\
African-American & $50 \%$ & $38 \%$ \\
Males & & \\
White Females & $74 \%$ & $68 \%$ \\
African-American & $66 \%$ & $46 \%$ \\
Females & & \\
\hline
\end{tabular}

brief aside, the 38\% FGR for African-American males in the nonathlete population should be of enormous concern to all who play a role in higher education.

The comparative graduation-rate findings reported above all use the FGR as the unit of measurement. This rate continues to be the only rate for which there is a direct comparison between the student body and the student-athlete populations. However, our membership has long believed that the FGR is an inadequate measurement of student success (for both athletes and nonathletes). For this reason, we were asked to develop a different measure of academic success that more accurately takes into account the variety of pathways that student-athletes might take to eventual graduation. This became the Graduation Success Rate (GSR).

The GSR was developed with several goals in mind. First, we wanted to get closer to a true student-centered graduation metric, as opposed to the institutioncentered FGR. The GSR was designed to deal with transfer students (both into and out of our institutions) in a much more realistic way than the federal rate. By including transfers, the GSR begins with a cohort that is 35-40\% larger than that defined in the FGR. It is important to note that the GSR is not a statistical manipulation of graduation data-it is simply a change in the cohort definition that we believe is more reflective of current educational realities. The calculation remains based on known academic outcomes of student-athletes within each potential graduation cohort. On average, GSRs tend to be between 15 and 20\% higher than federal rates with current GSRs for the overall student-athlete cohort of about $80 \%$.

As a check on the validity of the GSR as a measurement of academic success, we used the student-centered data collected in our Study of Collegiate Outcomes and Recent Experiences (SCORE) study of former student-athletes. In that study, we were able to track the long-term academic outcomes of a group of almost 10,000 former Division I student-athletes who had entered college approximately 10 years earlier. The SCORE data indicated that just over $60 \%$ of them graduated from their initial college within 6 years of enrollment, almost identical to federal graduation rates for the same cohorts. However, an additional $25 \%$ of these former studentathletes indicated that they had graduated from an institution that was different 
than the one in which they had initially enrolled. This puts our best estimate of the real, long-term graduation rate among Division I student-athletes at between 85 and $90 \%$, much closer to the GSR estimates of success than the FGR.

As we moved in the early 2000s from the third era of academic research into the fourth, there were two findings that we want to highlight because they played an important role in driving much of our recent work and somewhat changed our approach in both research and policy. The paper in this issue by Tom Paskus (2012) will discuss all of the work in that era in detail.

The first focus of the recent research grows from the finding that, while high school academic characteristics are fairly good predictors of freshman performance, they are not nearly as good at predicting graduation from college. This finding led to a significant change in the thinking of the NCAA about academic issues. The Association moved from what had been a considerable focus on freshman eligibility as the primary policy initiative for student-athlete academic success to a much broader look at academic policy. There was a realization that member colleges can only have minimal impact on what happens to student-athletes before they come to our institutions, so the NCAA should look much more closely at what happens to those student-athletes while they are on our campuses. Thus, the question becomes: How can we create policies, incentives, and best practices that inspire (and/or require) all NCAA constituent groups to place a primary focus on the academic success of student-athletes during their collegiate careers?

The second area of focus stems from our observations of fairly significant subgroup differences in academic performance. There are large observed differences by race/ethnicity, by sport group, by gender, and by many other characteristics. Some of these differences were fairly explainable by understanding differences in incoming academic characteristics among various constituent groups, but some were not. Thus, another driving goal of the fourth era of research was to better understand those differences and try to address them.

In his paper, Dr. Paskus (2012) will discuss some of the ways we've tried to deal with these and other issues.

\section{References}

National Collegiate Athletic Association. (1983). NCAA 1983 convention proceedings. Mission, KS: NCAA.

Oriard, M. (2012). NCAA academic reform: History, context and challenges. Journal of Intercollegiate Sport, 5, 4 -18.

Paskus, T. (2012). A summary and commentary on the quantitative results of current NCAA academic reforms. Journal of Intercollegiate Sport, 5, 41-53.

Petr, T.A., \& Paskus, T.S. (2009). The collection and use of academic outcomes data by the NCAA. In J. Hoffman, J. Antony, \& D. Alfaro (Eds.), Data-driven decision making in intercollegiate athletics (pp. 77-92). San Francisco, CA: Jossey-Bass.

Smith, R.A., \& Helman, J.W. (1987). A history of the freshman rule. Unpublished manuscript.

The National Commission on Excellence in Education, U.S. Department of Education. (1983). A nation at risk: The imperative for educational reform. Retrieved from http:// www2.ed.gov/pubs/NatAtRisk/index.html 